\title{
Impact of Classroom Management Training on Physical Education Trainees' Self-Efficiency Feeling
}

\author{
Mohamed Sami Bouzid, Maher Mrayeh, Nizar Souissi \\ Higher Institute of Sport and Physical Education Tunis, Tunisia \\ Email: med.sami.bouzid@gmail.com, mrayeh.meher@gmail.com, n souissi@yahoo.fr
}

Received 1 June 2015; accepted 30 June 2015; published 3 July 2015

Copyright (C) 2015 by authors and Scientific Research Publishing Inc.

This work is licensed under the Creative Commons Attribution International License (CC BY).

http://creativecommons.org/licenses/by/4.0/

(c) (i) Open Access

\begin{abstract}
This study measures the impact of an additional training in classroom management on physical and sports education trainees' self-efficacy feeling. An experimental group having received a complementary theoretical and practical formation in classroom management has been compared to a focus group which has followed the initial formation course. Two measures of this feeling have been taken at different moments by using the questionnaire Ohio State Teacher Scale (OSTES) translated in French. This device is made of three sub-scales of eight items each related to the teaching strategies adopted by the teacher in his classroom management and his capacity to involve the students in this task. The analysis allows the trainees who have received an additional training in classroom management to express a feeling of efficiency higher than those who received usual initial training.
\end{abstract}

\section{Keywords}

Training, Physical Education, Trainees, Classroom Management, Self-Efficacy Feeling

\section{Introduction}

We have been able to notice since a decade that the Tunisian Academic System has undergone deep structural changes. These changes, in connection with the Process of Boulogne and the implementation of the so-called "Bachelor's degree-Master's degree-Doctorate" better known as "LMD" have in particular affected the initial training for the teaching of Physical Education and Sports (PES). In the overall context of this LMD reform, the ministry orientation aimed at - among other things - the professionalization of training (Journal Official of the Republic of Tunisia JORT dated on 30/09/2008 No. 79). For the Tunisian Ministry of Higher Education, the 
whole academic training system must be adapted to the system of the European countries. However, the adoption of this new course of training by the Higher Sports and Physical Education Institutes (ISSEP), as a consequence, led to the shortening of the initial training in the teaching of physical and sports education. Indeed, the previous (old) course required four years of training in order to obtain the national degree of Master of Sciences (MSc) in Physical and Sports Activities (STAPS). At present, the LMD course offers three years of training in order to obtain a Fundamental Degree in physical education. This national diploma allows the successful candidate to practise the profession of PES on the same terms as a holder of a Master in STAPS. Nevertheless, this restructuring of the academic course has the effect of reducing the amount of hours destined to training from 3120 hours to 2268 hours leaving a less important place to the training component in practical environment. This considerable reduction of the time allocated to the initial training has consequently affected, very directly, the probation of practical pedagogy which, also, has been stripped of a considerable amount of hours, falling from 182 hours to only 112 hours. In turn, the activities linked to the sciences of educational intervention predicted in the programme of the Master course have been cancelled or reformulated in order to allow the reduction of the hourly amount of the initial training.

In this respect, most of the researchers who are interested in teacher training state that the professional skills are developed in practical environment (Ria, Sève, Durand, \& Bertone, 2004; Roux-Perez, 2006; Serres, Ria, Adé, \& Sève, 2006). Among these skills, classroom management is of considerable importance, both at the level of quality of teaching and at the level of student's learning (Martineau et al., 1999). According to Martin and Baldwin (1996), an efficient classroom management allows to create a clean learning climate, student centred, and maximize the learning time (Chouinard, 1999; Nault \& Fijakow, 1999). The negative repercussions due to an inefficient classroom management have been demonstrated repeatedly by the research. It also appears that teachers happen to lose more than $40 \%$ of the time allocated to learning due to poor classroom management (Léveillé \& Durfour, 1999). It is clear that the initial training must ensure to the better the development of this skill by providing a certain balance between the practical and the theoretical pedagogical practices. In the regard, it happens that the more complex the tasks are, the higher the classroom management skill must be. It is also recommended to sustain the development of this skill from the very first steps in the exercise of this profession as it would condition success in the teacher's career by establishing self-confidence (Nault \& Lacourse, 2008; Archambault \& Chouinard, 2009).

In this regard, the specificity of physical education makes the probation of practical pedagogy a suitable place where the student, by mobilizing his theoretical and practical knowledge, will be able to develop gradually his professional skills (Gervais \& Desrosiers, 2005). At this regard, Tardif (2006) considers the probation of practical pedagogy as a source of experiential knowledge, considered in itself as the basis of professional skill for skilled teachers. Its importance in terms of development of skill related to classroom management of future participants in the field of PES teaching is considered as crucial. Thus, we learn to teach in the first stages in the classroom and it is then that the set of the student's development process is involved (Ria et al., 2004).

Besides, in the Tunisian context, although many efforts were made a few years ago, in particular after the adoption of LMD course, the initial training of PES teachers is still limited mainly concerning classroom management which is not explicitly mentioned in the official programmes. Consequently, many trainees do not master enough this skill, which fact is confirmed by the several end-of-year training reports which state that these latter are lacking the skills required for the creation of a favorable teaching and learning atmosphere. However, if these official programmes mention a probation duration of 112 hours spread on the last training year, attention should be drawn on the fact that the hourly amount remains relatively theoretical. Actually, the trainees are unable to compatibilise 112 training hours spread out on one year since we must most probably deduce the periods where the educational institutions are in exam periods, therefore the students are unavailable, as well as the periods of bad weather since the majority of educational institutions do not have an indoor sports room. Another important thing to be taken into consideration, the trainees are supposed to teach four hours during the morning once a week, that is to say four 60-minute physical education sessions. However, due to lack of facilities, many trainees make only two hours of teaching followed by two hours of observation. At this level, the overall amount dedicated to probation is halved. In short, it is not rare to see some trainees compatiblise only half the time actually consecrated to the practical pedagogy probation.

Our perception to this fact is that classroom management has not really sparked the direct interest of Tunisian researchers. Thus, bearing in mind the application of the LMD system and its repercussions on the pedagogical training of PES teachers, it is highly relevant to ask oneself on the competence of the new trainees as far as 
classroom management is concerned. We think that it is important to support the trainees by offering them a pedagogical framing necessary to the development and the consolidation of this competence.

Inspired from the self-efficacy theory of Bandura (2007), we argued that this project of conceiving a training program could improve the trainees' feeling of self-efficacy concerning classroom management, this feeling being here a sign of improvement of this competence. In order to conceive this program, we have opted for this current study to appeal only to one source of information which has an impact on the auto-efficacy feeling, namely the "successful or controlled experience".

\section{The Theoretical Model of Classroom Management}

The training program relies on Wubbel's theoretical conception of classroom management (2005). It defines classroom management as being "the set of educational practices to which the teacher applies in order to establish and maintain an orderly learning environment and make an efficient use of the time favorable for the development of students' skills". The particularity of this model consists in its tight interest in the notion of order during the session. According to Doyle (1980), order is associated to the organisation of the classroom group, the setting of rules and procedures, the prevention and handling of behavioral problems together with the supervision. The notions of order and learning are tightly linked together. Indeed, according to Wubbels (2011), drawing and maintaining students' attention requires a minimum order so as to promote teaching and learning. Order also takes a social dimension in as much as it concerns a social construction which focuses on the fact that classroom activities are co-jointly constituted by participants (Erickson \& Shultz, 1981). In other words, inside the classroom, order is achieved with students and it depends on their willingness to follow the course of events. This implies, the, a certain cooperation between the teacher and the student. Besides, many researches on classroom management have shown that the necessity of resolving skilfully and cautiously problems linked to lack of discipline so as to create an orderly and smooth environment. It is evident, according to Wubbels (2011) that the big majority of teachers mention classroom management including students' indiscipline and misbehavior, as the most important problems which they face on a daily basis. This turns out to be true particularly in the case of beginning teachers who point out that classroom management is their foremost priority (Evertson \& Weinstein, 2006). Establishing and maintaining order in the classroom is indeed systematically linked to the student's implication and willingness to learn (Doyle, 1986).

In this perspective, efficient teachers show enough dexterity and teaching strategies to draw their students' attention to their task. They excel in the planning of their course and show a good sense of organisation; they also often offer useful suggestions to their students. At the start of the school year, they establish procedures, rules and routines in order to give their students more autonomy and thus allow them to gain time. They model the students' expected behaviour and when perturbations occur, they interfere rapidly and discreetly to stop them before they are transformed into serious problems. In short, as shown by Desbiens, Spallanzani, Roy, Turcotte, Lanoue and Tourigny (2014), their success in classroom management lies mainly on the fact that they use judiciously and efficiently the time allocated for learning and they exert a careful control on the important variables related to the learning context, the learning activities the interaction behavior as well as their perception by the students.

\section{Self-Efficacy Feeling}

In this orientation, in order to evaluate the teaching practices likely to implement school success, many researchers have opted for the personal efficacy feeling (Heneman III, Kimball, \& Milanowski, 2006; Dufour, 2010; Ménard et al., 2012). This socio-cognitive psychology concept has been strongly developed by Bandura $(1997,2007)$. The self-efficacy feeling is explained by the belief that one individual has in his capacity to succeed in a task, to act in such a way as to control the events which affect his existence (Bandura, 1997). Several researchers agree to say that i twill constitute one of the best indicators of good teaching practices. Indeed, if he believes in his capacities and skills to influence learning, the teacher can change and evolve in his practices, and this has inevitably an impact on students' involvement and success (Menard et al., 2012). As for Bandura (1994, 1997) four sources can strongly contribute to an individual's self-efficacy feeling: the successful or controlled experience, the vicarious or indirect experience, the verbal persuasion and the psychological state. In this respect, Menard (2012) reports in his works that the most determining source of influence would be the actually lived and successful experience. Indeed, the successful or controlled experience can build a strong feeling of self-ef- 
ficacy particularly if it presents a certain overcoming of current obstacles. In this case, a bad experience can have a positive impact in as far as it is perceived as an opportunity of development rather than an opportunity of failure. This type of experience teaches the individual that it is compulsory to make efforts in order to succeed. Several studies report that teachers who have a high feeling of self-efficacy are better equipped to face challenges in the school environment (Dufour \& Chouinard, 2013). Indeed, they manage to control the classroom more efficiently, among other things, and they are more dexterous in solving problems, by adopting more innovating practices. In short, if a teacher succeeds in preventing and anticipating behavioral problems linked to indiscipline by planning his management system, he will be less stressed, more efficient and motivated. From out viewpoint an additional training in classroom management should strengthen the feeling of self-efficacy for PES trainees at the end of their academic career.

\section{Research Objective}

This research aims at elaborating and experimenting a training program concerning classroom management by PES trainee students at the end of initial training. The specific objective of the study was to check the impact of the classroom management training program on the PES trainee students' personal self-efficacy feeling.

\section{Methodology}

This research consists in a quasi-experimental study for the fact that there is manipulation of a variable, namely the training program of classroom management, and that there is an observation of its effect on the self-efficacy feeling of trainees in physical and sports education. In order to measure the effect of the training program on the trainees' efficacy feeling, we have opted for a quantitative approach based on a questionnaire.

\subsection{The Training Program in Classroom Management}

For the current study, an additional training program in classroom management has been conceived in order to raise the PES trainees' feeling of self-efficacy (Villeneuve's process of integration of learning, 1994). Some training activities stemming from a theoretical model of classroom management have constituted the basis of meetings during the whole training period. The training program predicted 11 meetings, 7 of them lasting 2 hours and four of them lasting one hour and a half, which makes 20 training hours. The training started in September and it ended in March. During these meetings, many learning topics from a chosen model of classroom management have been raised. Since the lack of knowledge of procedures is often at the origin of various difficulties met in classroom management by beginning teachers (Chouinard, 1999; Lamarre, 2004), the appropriation of a theoretical content has constituted the first step of the program. Then, the implementation of the theoretical content in simulation of a real teaching session was the second step. It is by this implementation that the trainees have tried their chance at Bandura's theory of "successful and controlled experience" (2007). Indeed, each meeting is associated to a thematic content which was presented, worked, discussed and experimented. A training meeting implies a theoretical content followed by its implementation. By the 'active experience', the trainees are asked to plan, organize and supervise teaching sequences then, outside meetings, they were invited to implement the elements of content in their training environment. In order to have a more positive effect between the experience and the learnings, successes were systematically underlined while failures were discussed and analysed, thus allowing to make all the aspects of the training program constructive.

The originality of the training program consists in predicting the first meeting a week before the start of probation. The objective of this first training session was to plan an efficient system of disciplinary management in order to initiate i tat the first contact between the trainee and his students at the beginning of the school year. The trainees have been able to attend a first session of appropriation dealing with the teaching approach of rules and procedures in five steps: 1 -the oral and written presentation, 2-the link with previous knowledge, 3-the process, 4-the guided degressive practice and 5-the return on learnings. One should start by planning the first sessions of the year with the students in the classroom. According to Doyle (1980), the bases of an efficient classroom management lie on four processes. In order to assess a classroom atmosphere in which order and peer cooperation rule, one must meticulously prepare the start of the school year, choose and organise motivating learning practices, supervise the good process of these activities and know when to react efficiently to unruly behavior. 


\subsection{The Participants}

In this study, we have opted for a technique which does not admit probability. The sample is made of voluntary male and female students. They are training students at the end of formation in physical education and sports teaching and their age is $23 \pm 1$ year. Registered at their third year. They have filled in a questionnaire twice during the school year 2014-2015. For the first hand-out, they were 48 and for the second they were 37 . The sample is made of a first reference group and a second experimental group. At the start during the first handing of the questionnaire the reference group was $n=25$ ( 15 men; 10 women) and the experimental group was $n=22$ (9 men; 13 women). During the second handing of the questionnaire the reference group was $n=25$ and the experimental group was $n=12$ ( 5 men; 7 women). This could be explained by the lack of motivation of the group which was submitted to the training program as it had to attend the training sessions outside the course hours provided by the university and at their own expense.

\subsection{The Process of Data Collection}

All the participants have signed, by accepting to participate in the study, that they consent to reply to the questionnaire. The questionnaire has been, then completed in two times, on time during the second week of training, which corresponds to the second week of probation, and a second time one week after the end of training and probation. The questionnaire required about ten minutes to be completed. For a questionnaire which has been used as a pre-test, each one of the participants identified himself by a pseudonym in order to ensure anonymity and match the requirements.

\subsection{The Instrument of Data Collection}

In order to collect data, both groups have filled in the French version of Ohio State Teacher Efficacy Scale (OSTES). The OSTES was selected since its original version presented reliable and valid data conform to the requirements of the art. The translation of the original version of OSTES in French has been validated in 2010 (Ménard et al., 2012). In his works, Ménard et al. (2012) confirms that previous researches gave a coefficient for the set of the scale which is 0.89 for one case and 0.93 for the other case and a specific coefficient for three sub-scales which varied between 0.77 and 0.90 (Heneman III et al., 2006; Tschannen-Moran \& Woolfook Hoy, 2007). Moreover, what seemed to us so important, OSTES was recognised as an instrument to measure the teacher's efficiency?

The questionnaire is made of three sub-scales of eight items each. The first sub-scale measures the efficacy feeling with regards to the teaching strategies that the trainees use (for instance, in this course, do you consider yourself capable of replying correctly to the difficult questions your students ask?). The second sub-scale measures the beliefs and the practices related to the classroom management which evaluates the trainee students' efficacy feeling (for instance, in this course, do you consider yourself capable of calming down an unruly or restless student?). The third and last sub-scale measures their efficacy feeling concerning their capacity to maintain the students involved in learning activities (for instance, In this course, do you consider yourself capable of assisting the students in order to implement their success?). The answer scale is graded from 1 (not at all) to 9 (perfectly).

The verification of the internal coherence of each of the three sub-scales of the questionnaire (in Table 1) has been achieved by Cronbach's alpha according to Fortin (2010), a Cronbach's alpha of 0.75 is judged sufficient in order to adequately construct a given component, as for Nunally (1978) the alpha value can go down up to 0.7 for a good liability

\begin{tabular}{ccc} 
Table 1. Internal Coherence of the three OSTES sub-scales. \\
\hline $\begin{array}{c}\text { Cronbach's Alpha } \\
1^{\text {st }} \text { Handing }\end{array}$ & $\begin{array}{c}\text { Cronbach's Alpha } \\
2^{\text {nd }} \text { Handing }\end{array}$ \\
\hline Teaching Strategies & 0.70 & 0.88 \\
Classroom Management & 0.72 & 0.81 \\
Students' Involvement & 0.70 & 0.70 \\
\hline
\end{tabular}




\subsection{Performed Analyses}

Non parametric analyses (Siegel \& Castellan, 1988) have been performed in order to check the influence of the training program on the training students' self-efficacy feeling. The two groups have been compared by means of the U of Mann-Whitney and Wilcoxon's test. These non-parametric tests were appropriate if we consider the small size of the retained sample.

\section{Results}

The statistic analysis results have shown the significant differences at the level of the three OSTES sub-scales. Concerning the teaching strategies, the results show a significant difference $(p<0.001)$ in favour of training students who were submitted to the training program. These trainees show a higher self-efficacy feeling than the training students who were satisfied with just the initial training offered by the institution. As for the second OSTES sub-scale concerning the capacity to manage a classroom, the results show a significant difference ( $p<$ 0.001 ) in favour of training students who were submitted to the training program. These latter show a higher efficacy feeling than the trainees of the sample group.

For the third, OSTES sub-scale, the results also show a significant difference $(p<0.001)$ in favour of trainees involved in the program. They are more efficient than the sample group to involve the students in the learning tasks.

As significant differences between the two groups of the study have been revealed concerning their perception with regards to the teaching strategies that they use, their classroom management and their capacity to involve students in learning activities, we adopt the hypothesis according to which the program has a positive impact on the self-efficacy feeling.

\section{Discussion}

In the context where the initial training of future PES teachers in Tunisia is still limited in the field of professional skills, in particular in the field of classroom management and despite all the measures taken in order to make it a shared responsibility in the context of pedagogical and didactic renovation, an additional training program in classroom management seemed to be a promising project. The objective of this research was to find out to what extent this program reached its goals, namely its contribution in raising PES training students' selfefficacy feeling.

The results of this study are promising concerning the efficiency of the program which seemed to have improved the self-efficacy feeling of the PES training students who attended the training. Indeed, the training students involved in the program have shown significant positive changes as a result of this experience. One of the explanatory elements is undoubtedly the fact that in the absence of training in classroom management in the official programmes, the trainees of the experimental group have managed to build up and develop this crucial skill in the teaching field. Let us notice that it is recommended to support the development of the classroom management skill from the first steps in the performance of this job as it would condition the success in the teaching career by establishing self-confidence (Archambault \& Chouinard, 2009). Indeed, for Nault (1999), the classroom management skill is a skill that can be built and developed. It is particularly during the practical pedagogical training that trainees learn to teach in the early classroom experiences and it is at that moment that the set of the trainees' development process is involved (Ria et al., 2004). It is also during the first days of work that the trainees are confronted to problems of classroom management, in particular disruptive behavior (Desbiens, 2009) at the risk of having a feeling of in competence from the first days of work (Dufour, 2010).

Besides, the evaluation reports of the end-of-year pedagogical training clearly mention several difficulties expressed by the trainees in matters of classroom management throughout their training.

From our point of view, if the teacher's early career is rather vulnerable towards this feeling, a measure of support through a training program should strengthen this trainee's self-efficacy feeling.

If the results show that the trainees of the experimental group have performed better than the sample group by a higher self-efficacy feeling, it is because one of the strong points of the training consisted in preparing the trainees how to reduce disruptive behavior from the beginning of the school year. Indeed, the training program included a first meeting with the trainees the objective of which was to make the trainees establish routines, rules and procedures in order to set up favorable teaching and learning conditions. In this respect, Doyle (1986) stresses that the establishment of routines is a very important mechanism for the establishment and the mainten- 
ance of order in the classroom. Let us remind that the main goal of the project is based on Wubbels conception of classroom management (2011) which resides in the establishment and the maintenance of order in the classroom favorable to teaching and learning. According to Doyle (1986), the notion of order refers to a whole system of management with a preventive goal of which planning, organisation and supervision make up the key dimensions in order to obtain an ordered atmosphere. In this orientation, the training program by its 20 training hours divided into 11 meetings throughout the training, has allowed the students to consolidate their skills in the planning, organisation and supervision of everything. The results showed that, by having the possibility of testing their learning in a practical context, the trainees of the experimental group managed to raise their sense of leadership, which has consequently raised their self-efficacy feeling. The theoretical-practical nature of the program has allowed the trainees to set a link between the learning they achieved, their practices and the impact of their work on the students. It is by this direct experience (Bandura, 2007) and by the reflexive return on the practices that the trainees will have consolidated this self-efficacy feeling.

Concerning the first sub-scale which measures the trainee's self-efficacy feeling with regards to the teaching procedure that he uses (for instance: In this course do you feel capable of implementing the teaching strategies that you use?) even though in the sample group there was presented a higher self-efficacy feeling than the experimental group before the trial of the program, at the end of the training the trainees who were submitted to the formation program had a higher self-efficacy feeling than the other group. Indeed, the training program has allowed the trainees to develop their capacity in elaborating more efficient teaching strategies. At the beginning of the year, the notion of planning was set in front of the training program. The first two meetings were dedicated to this dimension of management with a return during the other training meetings. The program has allowed the trainees to enjoy success during the teaching activities and this consolidated their self-efficacy feeling together with their motivation to repeat the experience in the future. On this point, Bressoux and Dessus (2003) report that in Physical Education, it is for the teachers who plan their teaching that the learning task is better presented. They explain the task very well and give more precise indications and their feed-back is more adequate. Consequently, their students become more concentrated. This converges with the results found in this study which show that the trainees of the experimental group feel more capable than the sample group, for instance, to provide another explanation or another example when the students find difficulty to understand and thus, they manage to reply to the students' difficult questions.

Concerning the second sub-scale which measures the trainee's self-efficacy feeling with regards to his classroom management (for instance: in this course, do you feel able of controlling the behavior of unruly students?). The results show that, by the end of the training, control ability is higher for the trainees who were submitted to the training program. This result is based on the pertinence of the first meeting in the framework of the training program which dealt with the setting of favorable conditions of learning in particular by the teaching approach for routines and rules. Various researches have shown the importance of planning during the first days of the school year and its influence on the remaining part of the year. An efficient classroom management strongly contributes to the prevention of difficulties linked to indiscipline and would be the key to success for teachers (Nault \& Lacourse, 2008). In support to this idea, Archimbault \& Chouinard (2009) state that it is this fact which, distinguishes high level teachers from low level ones. Our perception was that the training program allowed the trainees to put into practice the elements of this first meeting before the beginning of the training: "rules are not made to be presented but to be taught to students". Our objectives seem to be reached, the trainees of the experimental group have learnt to take their time in order to implement routines, think and establish rules. The result is that, at the end of the training, they acquired an efficacy feeling of classroom management higher than that of the sample group.

Concerning the third and last sub-scale which measures the trainees' efficacy feeling with regards to their capacity to maintain the students involved in learning activities (for instance, In this course, do you consider yourself capable of assisting the students in order to implement their success?). The results have shown a significant improvement of the trainees who pated in the program. At the end of the training, they became more confident. The program predicted a training section on active supervision in pedagogy and this allowed the trainees to learn and implement efficient strategies in order to trigger students' interest and keep them involved in the task. Thus, they felt able to avoid the disruptive behavior of the students who were not involved and who potentially tended to favor indiscipline. This also agrees with Doyle's works (1986) which call to mind the importance of motivating the students to learn by using efficient strategies in order to get them involved in the task. At this point, a good organisation increases the focusing on the content and arouses the student's desire to learn (Nault \& Lacourse, 2008). 
Finally the trainees' exclusive participation in the program has contributes to increase the self-efficacy feeling. At the end of the training, they were more convinced of their capacity to clarify their expectations, to make students learn to behave correctly from the beginning of the school year, to establish routines which facilitate the progress of activities and to opt for strategies which make the students pay attention and get involved in the task. As for the trainees who did not take part in the activities of the training program, their perception remained stable all along the training.

\section{Conclusion}

This research had an objective to check whether the additional training program of classroom management could have an impact on the training students' self-efficacy feeling at the end of an initial training in physical education. For this purpose, a collection of data has been performed in two times, at the beginning and at the end of the practical pedagogy training, through a questionnaire including a scale of measurement of the self-efficacy feeling, the OSTES version translated in French.

Even though it can be improved, the training program has allowed to mitigate the lack of training with regards to classroom management in the initial training for the teaching of physical education and sports. The results of this study have shown that the trainees who took part in the program are better than those of the sample group by displaying a stronger self-efficacy feeling. By doing this, they have probably felt success in the tests during the training, motivating them to preserve this acquired experience.

We think that the first meeting in the framework of the pre-school program has played a key role. We tend to believe that the trainees have lived a good beginning of the school year with their students because they were well-prepared. They certainly implemented strategies so as to prevent difficulties and promote the creation of a well-arranged atmosphere of teaching and learning.

The results of this study are interesting since they meet the main functions of an efficient classroom management, that is to say establish and maintain a well-arranged environment which is favorable to learning.

On the other hand, we emphasize the fact that, within the framework of this study, one of the main hindrances is consisted in the limited number of participants required by the selection of a sample. It is then rather hard to generalize the results unless we resume the program on the basis of a larger number of trainees. Besides, the means to achieve this project were not always at hand. In addition to that, other data sources would have enriched the collection through the questionnaire, such as the performance of interviews with a group of training students, or conducting interviews with their teachers who are involved in the training. Despite these limitations, the project offers promising prospects concerning the implementation of the classroom management skill and could make up an interesting contribution for the advancement of knowledge in the particular context of the training of future Tunisian teachers.

Finally, we suggest that the university officials look for better devices which would allow to consolidate the professional skills of future PES teachers, mainly classroom management, and draw their attention to the modalities which promote the self-efficacy feeling. For the initial training, we have to insist on the importance of the role played by classroom management. Therefore, we highly recommend classroom management be integrated in a training module in official programs.

\section{References}

Archambault, J., \& Chouinard, R. (2009). Towards an Educational Classroom Management (3rd ed.). Boucherville, Quebec: Gaëtan Morin.

Bandura, A. (1994). Self Efficacy, In V. S. Ramachaudran (Ed.), Encyclopedia of Human Behavior (14, pp. 71-81). New York: Academic Press.

Bandura, A. (1997). Self-Efficacy: The Exercise of Control. New York : W.H. Freeman and Co.

Bandura, A. (2007). Self-Efficiency, the Self-Efficacy Feeling. Bruxelles: De Boeck University.

Bressoux, P., \& Dessus. P. (2003). Teacher Strategies in Interactive Situations. In M. Kail, \& M. Fayol (Eds.), Cognitive Science and School: The Question of Learning (pp. 213-257). Paris: PUF.

Chouinard, R. (1999). Beginner Teachers and Classroom Management Practices. Review of Educational Sciences, 25, 497514.

Desbiens, J. F., Borges, C., \& Spallanzani, C. (2009). Educational Supervision in Physical Education. Education and Francophonie, 37, 1-5. http://dx.doi.org/10.7202/037649ar 
Desbiens, J. F., Spallanzani, C., Roy, M., Turcotte, S., Lanoue, S., \& Tourigny, J. S. (2014). A Multi-Referenced Analysis of the Quality of Learning Climate in Health and Physical Education Student Teaching. Sport Science Review, 23, 5175-5204. http://dx.doi.org/10.1515/ssr-2015-0001

Doyle, W. (1980). Classroom Management. Document ERIC No. ED206567, Lafayette: Kappa Delta Phi.

Doyle, W. (1986). Classroom Organization and Management. In M. C. Wittrock (Dir.), Handbook of Research on Teaching (3rd ed., pp. 392-431). New York: Macmillan.

Dufour, F., \& Chouinard, R. (2013). Classroom Management Support System: Testing with Teaching Beginners. Education \& Formation, e-299, 52-66.

Erickson, F., \& Shultz, J. (1981). When Is a Context? In J. L. Green, \& C. Wallat (Eds.), Ethnography and Language in Educational Settings (pp. 147-160). Norwood, NJ: Ablex Publishing.

Evertson, C. M., \& Weinstein, C. S. (2006). Classroom Management as a Field of Inquiry. In C. M. Evertson, \& C. S. Weinstein (Eds.), Handbook of Classroom Management: Research, Practice, and Contemporary Issues (pp.3-16). Mahwah, NJ: Lawrence Erlbaum Associates.

Fortin, M. F. (2010). Fundamentals and Stages of the Research Process. Quantitative and Qualitative Methods (2nd ed.). Montréal: Chenelière Éducation.

Gervais, C., \& Desrosiers, P. (2005). The School, a Place of Teacher Training. Questions and Accompanying Benchmarks for Trainees. Sainte-Foy: Laval University Press.

Heneman III, H. G., Kimball, S., \& Milanowski, A. (2006). The Teacher Sense of Efficacy Scale: Validation Evidence and Behavioral Prediction. WCER Working Paper No. 2006-7, Madison, WI: University of Wisconsin-Madison, Wisconsin Center for Education Research. http://www.wcer.wisc.edu/publications/workingPapers/Working_Paper_No_2006_07.pdf

Lamarre, A. M. (2004). The Study of the Experience of the First Year of Primary Education in a Phenomenological Hermeneutical Perspective. Recherches Qualitatives, 24, 19-56.

Léveillé, C. J., \& Dufour, F. (1999). The Challenges of Managing Class in High School. Journal of Science of Education, 25, 515-532.

Martin, N. K., \& Baldwin, B. (1996). Helping Beginning Teachers Foster Healthy Classroom Management: Implication for Elementary School Counselors. Elementary School Guidance and Counseling, 31, 106-113.

Martineau, S., Gauthier, C., \& Desbiens, J. F. (1999). Classroom Management at the Heart of the Teacher Effect. Review of Educational Sciences, 25, 467-496.

Ménard, L., Legault, F., \& Dion, J. S. (2012). Impact of Teacher Training and Supervision in the Sense of Self-Efficacy of New Teachers College. Canadian Journal of Education, 35, 212-231.

Nault, T., \& Fijalkow, J. (1999). Introduction. Classroom Management: From Yesterday to Tomorrow. Review of Educational Sciences, 25, 451-466.

Nault, T., \& Lacourse, F. (2008). Classroom Management. A Skill to Develop. Anjou: CEC Ed.

Nunally, J. C. (1978). Psychometric Theory. New York: McGraw-Hill.

Official Journal of the Tunisian Republic (JORT) (2008). Order Fixing the General Framework of the LMD Studies System. Official Journal of the Tunisian Republic (JORT), 79, 3093-3098.

Ria, L., Sève, C., Durand, M., \& Bertone, S. (2004). Uncertainty, Contradiction and Exploration: Three Typical Experiences of Beginning Teachers in Physical Education. Review of Educational Sciences, 30, 535-554.

Roux-Perez, T. (2006). Representation of the Teaching Profession and Education in Relation to Students in STAPS: Professional Identity Construction. STAPS Review, 73, 57-69. http://dx.doi.org/10.3917/sta.073.69

Serres, G., Ria, L., Adé, D., \& Sève, C. (2006). We Learn to Really Be Involved in Initial Training? The Premises of the Development of Professional Activity in the Dual Training Devices. STAPS Review, 72, 9-20. http://dx.doi.org/10.3917/sta.072.09

Siegel, S., \& Castellan, N. J. (1988). Nonparametric Statistics for the Behavioral Sciences (2nd ed.). Boston, MA: McGraw-Hill.

Tardif, M. (2006). What Knowledge of Teaching Experience? Bulletin of the High School of Pedagogy Bern, Jura and Neuchâtel, 3, 13-16.

Tschannen-Moran, M., \& Woolfook Hoy, A. (2007). The Differential Antecedents of Self-Efficacy Beliefs of Novice and Experienced Teachers. Teaching and Teacher Education, 23, 944-956. http://dx.doi.org/10.1016/j.tate.2006.05.003

Villeneuve, L. (1994). Tools for Learning. Montreal: Editions Saint-Martin.

Wubbels, T. (2011). An International Perspective on Classroom: What Should Prospective Teachers Learn? Teaching Education, 22, 113-131. http://dx.doi.org/10.1080/10476210.2011.567838 


\section{Appendix}

French version of Ohio State Teacher Efficacy Scale (OSTES)

(Questionnaire enseignant stagiaire, sentiment d'auto-efficacité)

\section{VOUS DEVEZ RÉPONDRE EN FONCTION DE CE COURS}

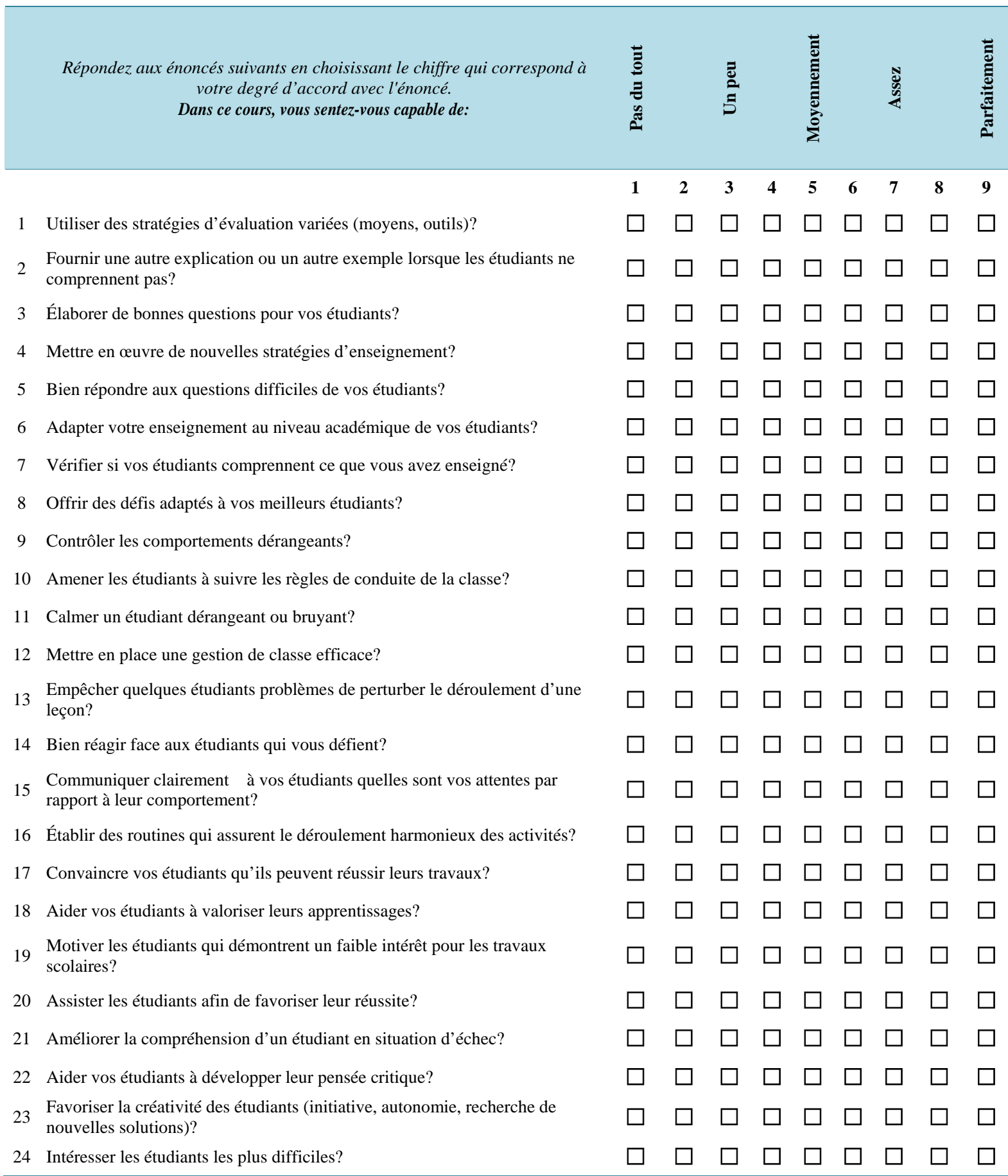

